\title{
PARADIGMAS EMERGENTES, CONHECIMENTO E MEIO AMBIENTE
}

\author{
Liane Keitel* \\ Reginaldo Pereira** \\ Ireno Antônio Berticelli***
}

RESUMO: Este artigo tem por objetivo estimular o debate sobre novos modos de se

*Mestra em Ciências Ambicompreender/tratar o mundo com os recursos científico-epistêmicos. Para tal, o estudo levanta e analisa novas formas de reclaionamento científico com o mundo, com fundamento em paradigmas emergentes em ciências, tais como a teoria dos sistemas de Bertalanfy, a teoria de auto-organização de von Foerster, Ilya Prigogine, Henri Atlan e Edgar Morin, do acaso e necessidade de Monod, de autopoiese de Humberto Maturana e Francisco Varela, com suas emergentes possibilidades epistemológicas e também educacionais. Utiliza-se o método reconstrutivo, ou seja, colocam-se em diálogo teóricos e teorias diferentes que possam fornecer sustentação argumentativa para a tese central defendida.

Palavras-chave: paradigmas em ciências, meio ambiente, complexidade.

\section{EMERGENT PARADIGMS, KNOWLEDGE AND ENVIRONMENT}

ABSTRACT: This article has the objective of stimulate the discussion about new ways of comprehending/discussing the world with scientific-epistemic recourses. For that very reason this study enlists and analyses new forms of scientifical acquaintence with the world, based on emergent paradigms in sciences, just as Bertalanfy's systems theory, theory of auto-organization of Ilya Prigogine, Henri Atlan and Edgar Morin, the random and necessity theory of Monod, the autopoiesis theory of Humberto Maturana and Francisco Varela, with theirs epistemological and also educational possibilities. The reconstructive method is used, that is, different theoretical authors, different theories are placed in dialogue with the objective of supplying argumentative support to the main thesis of this article.

Keywords: paradigms in science, environment, complexity. 


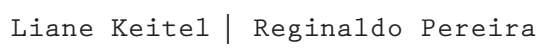

\section{INTRODUÇÃO}

O presente artigo procura, inicialmente, descrever as bases epistêmicas sobre as quais foi alicerçado o pensamento moderno, que determina, no mundo ocidental, as formas de reconhecer o que é e como se produz conhecimento científico, bem como alguns dos impactos sobre o pensamento educacional. Objetiva-se entender quais são as razões pelas quais esse método demonstrou ser tão eficiente em possibilitar o conhecimento sobre as mecânicas do mundo e, com isso, também apreender os mecanismos utilizados pelo homem para subjugar e utilizar os recursos oferecidos pela natureza. Além disso, busca-se perceber quais as consequências desses pressupostos na relação que o homem passa a estabelecer com a materialidade, com a natureza. As consequências produzidas sobre o homem e sobre o ambiente de praticamente trezentos anos de reinado da modernidade mostram os principais efeitos que a fragmentação e a compartimentalização dos saberes causaram à humanidade e ao planeta Terra e como essa forma de pensar apresenta-se ineficaz para dar conta, a longo prazo, dos problemas das sociedades arquitetadas sob seus princípios.

No intuito de se proporem alternativas ao paradigma newtoniano, apresentam-se conceitos que fundamentam a ciência da complexidade. Estes nascem a partir da ecologia, na tentativa de se explicitar que os fenômenos naturais e sociais, as relações estabelecidas entre o ser humano com outros de sua espécie ou com outras espécies ou, ainda, com os elementos abióticos da biosfera não se submetem a uma lei universal matematizadora e simplista, mas são essencialmente complexas e não podem ser analisadas a partir de matrizes fragmentadoras e reducionistas.

Para tanto, estudar-se-á, em um primeiro momento, a cibernética de primeira ordem baseada na teoria geral dos sistemas. Em seguida se analisarão as contribuições de vários autores para a formulação do que posteriormente se denominou de cibernética de segunda ordem, e/ou paradigmas da complexidade. Com isso, busca-se contribuir para consolidação de novas formas de se pensarem os fenômenos e de se estabelecer diálogo entre diferentes dimensões da realidade, que podem servir para discussão dos fazeres científicos em diferentes áreas.

\section{A CIÊNCIA MODERNA E O DISCIPLINAMENTO DOS SABERES}

Historicamente, as ciências em geral sofreram um processo de fragmentação disciplinar como um fim em si mesmo, o que trouxe como grande desafio para as universidades, no início do século XXI, superar o referencial linear cartesiano, que simplificou, individualizou e racionalizou a realidade, com intenso disciplinamento dos saberes. Esse gigantesco processo denominou-se modernidade. Segundo Frei Betto (1997), a modernidade foi preparada por três fatores: as descobertas marítimas, a criação das universidades e as corporações marítimas. A rai- 
nha das ciências passa a ser a física, e o conhecer sustenta-se na razão, buscando uma compreensão da mecânica do mundo através do pragmatismo que manipula e transformar o mundo. A modernidade diferencia-se da medievalidade, em que a rainha das ciências foi a teologia, e o conhecimento se fundamentou na fé, na contemplação de verdades reveladas.

A modernidade tornou-se, desde a sua gênese, um projeto ambicioso de se emancipar o homem de Deus. Com autonomia para produzir conhecimento, o homem passou a ocupar o lugar até então destinado a Deus, um Deus detentor de verdades. Um excesso de promessas, aliado ao déficit de cumprimento de várias delas, face à impossibilidade de serem efetivados valores tendencialmente contraditórios - justiça e autonomia; solidariedade e identidade; emancipação e subjetividade; igualdade e liberdade - fez com que este projeto entrasse em crise (SANTOS, 2003, p. 77-80).

Apesar de a modernidade não ter cumprido, no plano social, a totalidade de suas promessas, é inegável que marcou a forma da civilização ocidental no pensar e no fazer ciência, bem como todos os sistemas educacionais modernos. $\mathrm{O}$ método cartesiano simplificou, individualizou e racionalizou a percepção e apreensão das coisas do mundo. A modernidade inaugurou o diálogo experimental, firmado em estratégias de manipulação de variáveis da natureza e matematização de respostas dadas, sustentada no paradigma newtoniano. Newton, ao formular a teoria da gravitação, estabeleceu uma lei passível de ser aplicada tanto a objetos terrestres quanto a corpos celestes, e não foram poucas as tentativas de se aplicá-la em ciências humanas como a psicologia e mesmo a educação. Com base nessa teoria, Newton imaginou o universo como um grande relógio, sendo Deus o relojoeiro. Assim como um relógio, o universo possui uma mecânica interna que determina o seu funcionamento. Analogamente o universo também possui leis endógenas: quanto mais decompostas as coisas em seus mecanismos internos, melhor se conhecem. Newton sustentou seu enunciado em observações realizadas na fazenda de sua mãe e também nos estudos realizados por Copérnico e Galileu, segundo os quais a Terra gira em redor do seu próprio eixo e ao redor do Sol.

Prigogine e Stengers (1984) entendem que os frutos da modernidade são uma forte e cruel metáfora aplicada ao mundo, que define a natureza como autômata regida por leis acessíveis ao homem através de mecanismos racionais. Essa metáfora é complementada pela introdução da visão de Copérnico, a partir dos estudos astronômicos de Galileu Galilei, segundo os quais a Terra gira em redor do seu próprio eixo ao redor do Sol e todos os movimentos obedecem à lei universal dos corpos celestes e do mundo sublunar. Com isso, chega-se à conclusão de que todos os movimentos obedecem à lei universal dos corpos celestes e do mundo sublunar.

A simplificação permitiu a inferência de que a melhor maneira de se conhecer determinada coisa seria decompô-la em seus elementos e subelementos, pois o todo nada mais seria do que a soma das partes, já que obedecem a uma mesma 
lei. Além disso, a análise compartimentada apresentava-se como uma possibilidade vantajosa frente a questões científicas e econômicas. Esses fatores foram decisivos para que a ciência moderna adquirisse suas características básicas: a decantação, a decomposição e a fragmentação. Contudo, na contemporaneidade, cresce o número daqueles cientistas e educadores de diferentes áreas das ciências que nos oferecem convincentes e a abundantes conceitos capazes de dar sustentação argumentativa a uma visão do mundo (de toda a natureza) em sua complexidade plena. Não havendo aqui espaço para um levantamento extenso, mencionamos alguns dos principais autores e respectivos conceitos que oferecem tais perspectivas: a teoria do caos e dos fractais, de Edward Lorenz e Benoit Mandelbrot, respectivamente; o princípio da complexidade por auto-organização pelo ruído (ordem pelo ruído), desenvolvido por Henri Atlan, segundo o qual, todos os seres vivos são sistemas auto-organizantes, constituindo esta propriedade a base dos processos evolutivos; a autopoiese de Humberto Maturana e Francisco Varela, conceito segundo o qual todo sistema vivo se autoproduz, de conformidade com sua estrutura interna; as estruturas dissipativas ou teoria do não equilíbrio (ordem por meio das perturbações), de Ilya Prigogine (Prêmio Nobel de 1977) segundo a qual sistemas distantes do equilíbrio, inclusive a matéria inorgânica, evoluem, pela auto-organização; os conceitos de acaso e necessidade, do biólogo também Prêmio Nobel, Jacques Monod.

Asssim, pode-se estender a lista de confiáveis cientistas que nos fornecem outra visão da natureza, longe da fragmentariedade proposta pela ciência moderna clássica. Este é o tipo de olhar com o qual pretendemos seguir, neste estudo.

Na esteira da ciência moderna clássica, entusiasmado por obter respostas, o homem isolou-se no universo como sujeito pesquisador, transformando a res extensa em objeto passível, à mercê da res cogitans (o ser racional/pensante), que a iluminava com as luzes da razão, para determinar-lhe a natureza. Esse método aplicou uma podeosa e cruel metáfora sobre o mundo, definindo-o por sua pretensa natureza autômata, regido por leis acessíveis ao homem por meio de mecanismos racionais. Diz Whitehead:

Assim, os corpos são percebidos juntamente com as qualidades que na realidade não lhes pertencem, qualidades que de fato são apenas produtos da mente. Assim, a natureza ganha mérito que na verdade deveria ser reservado a nós: a rosa por seu perfume; o rouxinol por seu canto; e o Sol por seus raios. Os poetas estão inteiramente enganados. Deveriam dirigir as suas líricas a si mesmos e deveriam transformá-las em congratulações a si próprios pela excelência da mente humana. A natureza é uma coisa enfadonha, sem som, sem odor e sem cor; mero passar da matéria, sem fim nem significação (2006, p. 75)

A opção por se tratar a natureza como enfadonha, surda, muda, passiva, estúpida e sem encantamento foi aceita na medida em que o homem acreditou que iria encontrar certezas, e, com isso, poderiam ser controladas as forças misteriosas da natureza que constantemente ameaçavam a hegemonia do poder divino e, portanto, os interesses da Igreja. Tal fato demonstra como ciência e a cultura se retroalimentam e se reforçam mutuamente, possibilitando sucesso pelas inter- 
pretações que são possíveis de dar às teorias científicas na época histórica de sua produção (PRIGOGINE e STENGERS, 1984, p. 1-15).

A ciência faz parte do complexo da cultura a partir do qual esta tenta encontrar coerência intelectual e ordenar as vias pelas quais orienta sua investigação. Há uma retroalimentação por ressonâncias, pelas interpretações dadas, em cada época, às teorias científicas, e a educação tem sido encarregada, em todos os tempos, de reproduzir os ideais sociais, econômicos e políticos predominantes.

Um olhar fragmentário sobre o mundo acaba transformando, segundo Frei Betto (1997, p. 5), o todo nas suas partes, ou seja, veem-se as árvores, mas não se percebe a floresta, veem-se os diferentes sistemas que fazem parte do corpo humano, mas não se consegue ver a inteireza do ser humano. Perde-se a visão de conjunto de tudo.

O conhecimento organizado em disciplinas circunscreve vários elementos em campos distintos e, não poucas vezes, estanques como se fossem totalmente independentes. A tematização da inter/multi/transdisciplinaridade é um fenômeno bastante recente. A ciência assume posição de neutralidade e entende-se distinta da cultura, aniquilando os saberes locais e o senso comum, separando:

- o mundo da ciência do mundo da vida, com uma produção científica esterilizada, livre dos problemas do cotidiano, da realidade em sua dimensão concreta, histórica e cultural. (KOIRÉ, apud PRIGOGINE e STENGERS, 1984);

- o mundo físico do metafísico e ciências humanas das ciências da natureza. A dissociação do mundo dos conceitos do mundo físico está na raiz do fenômeno da destruição do meio ambiente, permitida pela razão instrumental, que se utiliza da natureza e ao manipulá-la a destrói. Não mais se percebe que “[...] nós somos seres da e na natureza, fazemos a natureza, fazemos a nós e ao nosso próprio corpo" (FREI BET'TO, 1997, p. 3). Para Fazenda (1994), isso reduziu o eu, o ser ao penso, e a produção do conhecimento ao pensar, ao intelecto, à razão, excluindo-se o sentir desse cenário:

Conheço minha exterioridade e nela construo meu mundo, um mundo sem mim, um mundo que é eles, porém não sou eu, nem somos nós. A razão alimenta-se até exaurir-se de objetividades. Quando nada mais resta, tenta lançar mão da subjetividade, porém, ela não é alimento adequado, porque adormecida, porque entorpecida. O beijo que tenta despertar a subjetividade adormecida acontece com a criação de algumas ciências (tais como a psicologia - início do século XX - construída a partir dos critérios clássicos da objetividade). Sucedem-se as tentativas, porém os produtos acabam sendo artes sem alma, psicologias sem espírito, religiões sem Deus, e ciências sem homem (p. 16).

O que Fazenda nos coloca é de suma importância. A autora mostra as consequências criadas para a vida de todo o planeta e para o viver das pessoas. Prigogine e Stengers salientam esse fato, entendendo que a existência da ciência e o conteúdo nela produzido definem as relações que o homem estabelece com o mundo e mantém com a natureza, e que estabeleceu as bases para a industrialização: 
[...] construiu-se uma cultura de exploração que se aprofunda na modernidade, que só na contemporaneidade tem começado a ser objeto de análise pelo próprio homem. Esta forma de ser e estar no mundo define uma consciência antropocêntrica, onde não somos capazes de perceber a realidade numa perspectiva holística. É preciso desenvolver uma consciência ecológica profunda, transpessoal (que transcenda a pessoa), que possa perceber que fazemos parte e que somos também o ambiente que construímos e que estamos reciprocamente relacionados, homem e natureza fazem parte de um sistema complexo de relações de mútua correspondência, e, portanto ações de expropriação e exploração não são contra a natureza, mas contra nos mesmos $(1984$, p. 8).

Morin (2002, p. 19) enfatiza que o problema humano abordado pelas ciências “[...] não é somente de conhecimento, mas de destino. Efetivamente, na era da disseminação nuclear e da degradação da biosfera, tornamo-nos, por conta própria, um problema de vida e/ou morte". Os grandes problemas ambientais são problemas humanos, que têm em seu cerne os conceitos que temos de ambiente e da relação, ou não, com a natureza, com a própria dimensão material, sentindo essas dimensões integradas ou não. A possibilidade de nos sentirmos parte da natureza define uma consciência ecológica, entendendo que fazemos parte da mesma casa (óikos, em grego, de onde: oikologia - ecologia - a ciência de bem gerir a casa). Isso é fundamental para redefinirmos nossa atitude de pesquisadores e/ou profissionais, ou educadores, visto que o contrário fundamenta uma base instrumental, que nos coloca numa perspectiva de sujeito-objeto, ao passo que a consciência ecológica nos desafia "[...] a aceitarmos o outro como legítimo outro na convivência” (MATURANA, 1999), e com isto o desafio é o de nos colocarmos como pesquisadores profissionais em relações sujeito-sujeito, em contraposição à separação sujeito-objeto, que define a forma de pensar da ciência moderna bem apresentada por Morin:

O âmago do paradigma da simplificação [...] que separa o objeto do seu meio, separa o físico do biológico, separa o biológico do humano, separa as categorias, as disciplinas, etc. A alternativa da disjunção é a redução: este tipo de pensamento reduz o humano ao biológico, reduz o biológico ao físico-químico, reduz o complexo ao simples, unifica o diverso [...], as operações comandadas por este paradigma são principalmente unidimensionais. Obedece-se apenas ao princípio da disjunção chega-se a um puro catálogo de elementos não ligados, se obedece ao princípio de redução, chega-se a uma unificação abstrata que anula a diversidade. Por outras palavras, o paradigma da simplificação não permite pensar a unidade na diversidade ou a diversidade na unidade, a unitas multiplex. [...] o "grande paradigma do Ocidente" que Descartes formulou quando afirmou a não comunicabilidade entre o domínio do sujeito que era o da cogitação, da filosofia, e do domínio do objeto, da coisa extensa, que era do domínio da ciência. A disjunção entre o sujeito (ego cogitans) e o objecto (res extensa) remetia o primeiro para a filosofia e o segundo para a ciência, mutilando uma e outra; daí este divórcio, trágico para ambos, entre ciência e filosofia (2002, p. 31).

Segundo Frei Betto (1997, p. 2), "Todos nós somos filhos da modernidade. Nossa estrutura de pensamento é moderna, mas nem sempre foi assim, e nem em toda parte do mundo é assim". Nessa perspectiva, pensar os grandes problemas da humanidade consiste em desconstruir as reduções e construir novas formas 
de pensar o mundo, a vida, que permitam a percepção da complexidade dos fenômenos, como citado anteriormente por Morin (2002, p. 31), estabelecendo-se a reconstrução das cesuras criadas pela fragmentação, a fim de que sejam obtidas respostas aos problemas que assolam o planeta Terra. Por consequência, educar, hoje, significa, em boa medida, reeducar, e, para reeducar, há que, muitas vezes, desconstruírem-se conceitos que a tradição moderna naturalizou, mercê de uma lógica da identidade em que as diferenças são por ela diluídas, com a exclusão de muitos e de muitas coisas cuja legitimidade se evidencia por outra lógica: a da diferença.

\section{Modernidade em colapso: o desenvolvimento de paradigmas ecológicos para constituição de diálogos}

O início do século XX foi marcado pelo surgimento de teorias que questionavam o método moderno de ciência. Destacam-se para este trabalho estudos sistematizados teoricamente a partir da ecologia. Von Foerster, (2000), classifica esse movimento em cibernética de primeira e de segunda ordem.

\section{Quadro 1 - cibernética de primeira e de segunda ordem}

\begin{tabular}{|c|c|}
\hline Cibernética 1aㅡordem & Cibernética $2^{\underline{a}}$ ordem \\
\hline Os sistemas: & Os sistemas: \\
\hline - São abertos e fechados & $\begin{array}{l}\text { Têm capacidade auto-organizativa, e como sistemas autopoiéti- } \\
\text { cos têm propriedades intrínsecas para a autocriação. }\end{array}$ \\
\hline $\begin{array}{l}\text { - Têm propriedades homeostáticas e } \\
\text { adaptativas. Homeostase refere-se ao } \\
\text { mecanismo que permite manter a sua } \\
\text { adaptabilidade face às modificações } \\
\text { internas e externas. }\end{array}$ & $\begin{array}{l}\text { - Constituem-se a partir da natureza dos processos de interação } \\
\text { entre seus elementos, e os estudos sobre a transferência de } \\
\text { calor a partir da termodinâmica ajudam a entender os organis- } \\
\text { mos como sistemas biológicos fechados em sua organização, } \\
\text { mas abertos para comunicação e relação, o que define uma per- } \\
\text { spectiva autoeco-organizativa. }\end{array}$ \\
\hline - Buscam o equilíbrio e a estabilidade & $\begin{array}{l}\text { - São definidos por estados de instabilidade e estão em con- } \\
\text { stante mudança, mais que em estado de estabilidade e equi- } \\
\text { líbrio. Homeostase significa igualmente um mecanismo de } \\
\text { adaptabilidade que está permanentemente confrontado com } \\
\text { crescimento, colocando a tônica entre equilíbrio dinâmico entre } \\
\text { adaptabilidade e mudança. }\end{array}$ \\
\hline - Evoluem a partir de leis gerais, & $\begin{array}{l}\text { - Evoluem por assimilação do ruído, por necessidade ou acaso, e } \\
\text { como uma co-construção de novas realidades. }\end{array}$ \\
\hline $\begin{array}{l}\text { - Colocam o observador à parte do ob- } \\
\text { servado. }\end{array}$ & $\begin{array}{l}\text { - Consideram que a realidade advém do domínio linguístico } \\
\text { através de processos recursivos de construção desta, sendo o } \\
\text { observador participante ativo da realidade criando e estabele- } \\
\text { cendo distinções que constroem a realidade. }\end{array}$ \\
\hline
\end{tabular}


Para aprofundar a compreensão acerca da cibernética de primeira ordem vamos explorar as ideias de Bertalanffy (1977, p 132), que, através da teoria geral dos sistemas, estruturada em 1928, defende a necessidade de construções ou modelos teóricos passíveis de generalizações e interdisciplinares, aplicáveis a fenômenos de diversos domínios. Define sistema como um "[...] complexo de elementos em interação formado por um total de partes que se inter-relacionam (BERTALANFFY, 1977, p. 84)". Um sistema, que pode ser um organismo, grupos de indivíduos, ou comunidades das mais diversas espécies contém subsistemas, que são conjuntos menores de elementos, e está inserido em suprassistemas, que são sistemas maiores, que o envolvem. Em ciências humanas e sociais são exemplos a comunidade, a escola e outras instituições, e, em ecologia, um bioma. O comportamento do sistema modifica os atributos dos objetos que compõem o meio, bem como a modificação desses atributos afeta o sistema.

A perspectiva sistêmica apresenta um modelo que restabelece a relação entre todo e parte. Além de pertencer a um todo, a parte pode ser um todo. $\mathrm{O}$ todo pode ser uma parte, dependendo da relação que tem com outros elementos. Cada qual contém em si aspectos de um todo e de uma parte. Todo, igual a hólon (em grego), remete ao que se denomina de visão holística. Hólos quer dizer todo, e ón quer dizer o ser, parte, parte que contém a tendência à autonomia e à integração ao todo (tó ón, em grego - o ser). Segundo Arthur Kaestler, Yano, deus da mitologia grega, é uma metáfora da característica do hólon, pois tinha duas faces voltadas para seus opostos, uma para autonomia (parte), outra para integração (busca do todo).

Os sistemas podem ser abertos e fechados. Os sistemas abertos são aqueles que estão em relação permanente com o exterior, implicando naturalmente uma grande exposição à mudança e um apelo importante à criação. Os sistemas fechados dizem respeito aos conjuntos fechados ao exterior, isolados e encerrados sobre si próprios. A comunicação com o exterior é definida pela fronteira ou limite, que é uma espécie de envelope que define claramente o que pertence ao sistema e o que pertence ao meio (sistemas circundantes), o que é próprio de cada subsistema. Essas são regras que definem quem participa do subsistema e como o faz, protegendo e mantendo a integridade. Um sistema aberto e hierarquizado é aquele cujas fronteiras funcionam como uma membrana semipermeável (permitindo trocas constantes com o meio) e em que há uma hierarquia integrada de subtotalidades autônomas (subsistemas).

Os sistemas mantêm-se e funcionam a partir de distintas propriedades. Uma delas é o princípio da totalidade - o sistema não é a simples soma dos seus elementos. O sistema não se comporta como um simples agregado de elementos independentes, mas constitui um todo coerente e indivisível. A interação não é um derivado de propriedades individuais, pois não se verificam relações unilaterais nos sistemas. A modificação de um dos elementos corresponderá a uma modificação de todos os outros e das relações entre eles, ou seja, do próprio sistema. O segun- 
do é o princípio da equifinalidade - princípio a partir do qual “[...] um mesmo ponto pode ser alcançado, seja a partir de condições iniciais diferentes ou a partir de caminhos diferentes" (BERTALANFFY, 1977, p. 182). Quanto às condições de estabilidade, aposto a um sistema fechado, cujo equilíbrio depende das condições iniciais, um sistema aberto pode atingir um estado temporalmente autônomo, independentemente das condições iniciais, e determinado unicamente pelos parâmetros do sistema.

À teoria geral dos sistemas, de Bertalanffy, agregam-se as ideias da cibernética, que advêm das analogias feitas entre máquinas artificiais e organismos vivos a partir da obra de Wiener (1948, apud ATLAN, 1992) e, também, da introdução das ideias de circularidade definida como troca de informação que definem o terceiro princípio, o da retroação - encadeamentos causais circulares - que permitem explicar um bom número de regulações biológicas que se agrupam definindo o quarto princípio, o da homeostase, princípio pelo qual o sistema busca manter um funcionamento fisiológico constante. A retroação explica a interação dinâmica de seus componentes.

Uma cadeia em que o evento $a$ gera o evento $b$, e $b$ gera então $c$, e $c$, por sua vez provoca $d$ etc., teria as propriedades de um sistema linear determinístico. Se, porém, $d$ conduzir de volta a $a$, o sistema é circular e funciona de um modo inteiramente diferente (WATZLAWICK, s/d, p. 27)

Em uma cadeia causal, um elemento age sobre uma etapa anterior do processo modificando-lhe o curso ou a estrutura. A retroação é um mecanismo de ligação, de unificação dos elementos do sistema (que não é somativo, nem unilateral - modelo de causalidade circular). A retroação pode ser negativa e positiva. A primeira é relativa aos mecanismos que permitem ao sistema se autocorrigir de modo a manter a sua estabilidade, enquanto a segunda diz respeito aos mecanismos que permitem ao sistema desorganizar-se e mudar.

Os organismos vivos, ao interagirem com outros sistemas circundantes, recebem e enviam informações, mantendo um ciclo de retroação, um feedback positivo ou negativo, que altera ou mantém o estado e a evolução do sistema. Segundo Watzlawick (s/d), a circularidade define-se como retroalimentação positiva ou negativa. A negativa busca a manutenção da estabilidade das relações buscando a homeostase, que busca manter o estado do organismo, na sua morfologia e nas suas condições interiores apesar das perturbações exteriores, enquanto a retroalimentação conduz aos processos de mudança pela perda da estabilidade ou equilíbrio, ou seja,

[...] na retroalimentação negativa, a informação é usada para diminuir o desvio do produto de um conjunto de normas e tendências - daí o adjetivo "negativo" - enquanto que, no caso de retroalimentação positiva, a mesma informação atua como medida para ampliar o desvio do produto e, por conseguinte, é positiva em relação à tendência já existente para um ponto morto ou disrupção [...] (WATZLAWICK, s/d, p. 27). 
Outro princípio de funcionamento dos sistemas é o princípio da morfogênese, que diz respeito ao mecanismo pelo qual ocorrem, em um sistema, transformações por retroação positiva, que conduzem ao aparecimento de novas estruturas. Esse é um mecanismo particularmente ativado pela necessidade de adaptabilidade suscitada pelas diferentes passagens de um estádio ao outro do ciclo vital. Como se vê, essa noção é complementar à noção de homeostase. As trocas são definidas pelo princípio da interação, como uma série de mensagens trocadas entre os indivíduos, em que cada um especifica o sentido dos outros. A partir dos estudos da termodinâmica, a comunicação dos organismos se define a partir das transferências de calor.

Ainda de acordo com Watzlawick, a questão central é o fato de que sistemas ecológicos, humanos, grupais e outros podem ser encarados como circuitos de retroalimentação, definindo que o comportamento de cada um afeta e é afetado pelo comportamento do outro. Segundo Ávila (1999, p. 229): “[...] uma das consequências da teoria dos sistemas foi ressaltar o risco da análise parcelada dos sistemas complexos, rompendo-se a unidade holística e impedindo a compreensão de certos fenômenos e propriedades que resultam, exatamente, de um determinado grau de complexidade ou organização". A teoria geral dos sistemas tentou verificar o conhecimento científico como resposta ao reducionismo, à linearidade, integrando uma epistemologia circular, não causalista, e sistêmica, buscando a unificação e integração mais ampla, criando um modelo explicativo da realidade que pudesse dar base para se entenderem vários segmentos e ser utilizado em várias áreas do conhecimento. No entanto, ainda se mantém, segundo von Foerster (2000), o pesquisador como um observador à parte do sistema, analisando o seu funcionamento.

Em um segundo momento, temos os conceitos da cibernética de segunda ordem, que definem formas diferentes de se pensar a realidade, o funcionamento do mundo e das coisas, cria novas formas de se entenderem os fenômenos e de se fazer ciência, buscando respostas para as inquietudes do início do século XXI. Segundo on Foerster (2000, 1996), a cibernética de segunda ordem atenta para o observador (diretor) que cria e estabelece distinções que criam a realidade, dando ênfase à inclusão e participação do observador no sistema, a partir da autorreferência, dos processos recursivos, e a construção da realidade.

Os processos recursivos, segundo Varela (2000, p. 150-154), são distintas formas de circularidade definidos por níveis de reflexividade. Uma delas é a circularidade lógica, que mantém a separação entre operados e operadores e os processos e resultados em níveis diferentes. A segunda forma é circularidade como fechamento operacional, a partir da qual não se descreve um sistema em termos de inputs e outputs, mas sim como sendo constituído pelas próprias ações, de modo que todas as significações de seu mundo são inseparáveis de suas próprias ações e não vêm do exterior. A partir da circularidade de segundo grau, advindo das ideias de von Foerster, o observador passa a ser entendido como parte da des- 
crição. Varela clareia a inclusão, definindo-a como as práticas humanas linguísticas e não linguísticas, o corpo, o tempo e o espaço. A emergência do ser humano acontece nesse espaço. Os processos recursivos chamam atenção para a separação sujeito-objeto como modelo de pesquisa, bem como para a incoerência em se dissociar o humano do ambiente. Transcende-se da cibernética para as narrativas. Nesse espaço se localiza a construção de conhecimento, não mais como a verdade sobre o mundo, mas o possível que nossos olhos podem ver e traduzir em linguagem.

Outra ideia importante da cibernética de segunda ordem, segundo Boscolo (2000), que advém de Maturana e Varela, é de que a realidade provém do domínio do linguístico, das conversações em busca de consenso. Há tantas realidades quanto há conversações. A evolução é uma coconstrução de novas realidades. Depreende-se daqui que os educadores, profissionais da conversação e do diálogo, necessitam estar atentos para os discursos que produzem, pois, com sua capacidade produtiva, a linguagem produz efeitos - a linguagem é pragmática.

\section{AUTO-ORGANIZAÇÃO/AUTOPOIESE: NOVAS POSSIBILIDADES EPISTEMOLÓ- GICAS, NOVAS LEITURAS DO MUNDO}

Monod (1989) aborda a relação entre acaso e necessidade, entendendo que acontecimentos importantes definem e redefinem a estrutura do indivíduo em inscrições no DNA, que é multiplicada e transportada aos descendentes. Com isso, propõe uma teoria da evolução baseada na comunicação entre os seres vivos, contrária às ideias de Darwin, que fundamenta a evolução como consequência da luta pela sobrevivência. Insere a humanidade e evolução dos sistemas como fruto de processos comunicativos contínuos de complexificação e auto-organização, ao longo de séculos de transformações que aconteceram por escolhas entre o acaso e a necessidade. Esse processo define linguagem e conhecimento nas mais distintas formas de vida.

Segundo Prigogine (2000, p. 209-215, 1996 p. 25-40, p. 257-269) e Prigogine e Stengers (1984), a lei do movimento de Newton $\mathrm{f}=$ m.a é uma lei temporalmente reversível e de caráter determinista, pois define que conhecidas as condições iniciais é possível prever qualquer posição passada ou futura de uma trajetória. No entanto, a partir da segunda lei da termodinâmica sobre estudos da transferência de calor, verificou-se que o tempo define novos níveis de organização, criando, preservando ou destruindo, possibilitando processos de organização espontânea e das estruturas dissipativas, que nascem do acaso e da necessidade. Tal perspectiva, além de reintroduzir a noção de um tempo não causal linear, possibilitou entender a transferência de calor e entropia como comunicação entre os organismos.

A partir daí surgiram novos conceitos acerca de sistemas: os sistemas dinâmicos e os sistemas caóticos ou estruturas dissipativas. Os sistemas dinâmicos 
dividem-se em simples e diferenciados. O primeiro é mais restrito a sistemas mecânicos, nos quais podemos pensar em leis gerais e em movimentos previsíveis, como o movimento da Terra. O segundo refere-se a sistemas do meio ambiente terrestre, constituídos por dinâmicas diferentes, como as condições do tempo que são previsíveis apenas por um curto lapso de tempo. Os sistemas caóticos são ligados à imprevisibilidade temporal, sendo impossível definir trajetórias e leis, mas somente fluxos de correlações que se tornam cada vez mais complexos, similares à noção de comunicação, a rede de interações complexas sem definição de causa e efeito, o que conduz a estruturas que podem ser muito complexas. Essas diferenciações possibilitam entender a complexidade distinta de organização e funcionamento da matéria.

Para Henri Atlan (1992) os sistemas complexos se situam entre a ordem simétrica de um cristal e a desordem e imprevisibilidade da fumaça. A ordem do cristal enseja a repetição, a regularidade e a redundância; enquanto a desordem da fumaça enseja a variedade, a improbabilidade e a complexidade. Em uma "organização dinâmica”, haveria uma coexistência desses ingredientes opostos.

Boscolo (2000), baseado nos estudos de Anderson-Goolishiam, entende que o sistema foi criado pelo problema e não o contrário. Ao invés de considerar que o indivíduo, a família e/ou comunidade engendram um problema, o sistema é criado pelo problema e, portanto, pode emergir não somente um sistema formado por pessoas, mas por ideias e por tudo aquilo que essas implicam, caracterizado por linguagem e apresentação. Por conta de tal característica deve o pesquisador inserir-se dentro do sistema, trabalhando de forma localizada e regional quebrando generalizações transformadas em metanarrativas. Deve-se salientar que essa noção vem ao encontro do pensamento de Morin, segundo o qual cada sistema funciona a partir de interações específicas construídas pela interação de seus elementos.

Odum (1971, p. 7), ao conceituar meio ambiente, faz isso sob o princípio da integração funcional, formulado por Fiebleman, segundo o qual haveria uma necessária interação entre unidades menores e maiores de um dado sistema, bem como um sistema de maior complexidade seria maior do que a simples soma dos seus elementos ou sistemas de menor complexidade que os integram.

Cada sistema possui mecanismos de regulação responsáveis pela escolha das possíveis respostas a fim de recolocá-lo em um estado aceitável. Atlan (1992, p. 37-52), ao descrever o movimento desses mecanismos, constata que o organismo, em sua interação com o ambiente, terá a tarefa de resolver os ruídos geradores de problemas/desestabilização advindos das relações mantidas com o meio. Os ruídos são importantes para a evolução de um sistema, pois, a partir deles, uma nova informação chegará e terá de ser assimilada. A absorção de um ruído gera desordem e, um organismo, ao assimilar um ruído pode ascender a novos níveis de organização e aumentar a sua complexidade. Essa possibilidade somente será viável a sistemas abertos, em comunicação com o meio ou outros organismos. Quanto 
maior a comunicação, maior a circulação energética. O ruído possui qualidades ambíguas: por um lado pode ser destrutivo se a perturbação for excessiva; por outro, necessário para que se chegue a níveis mais complexos de organização, pois somente a partir da desordem os sistemas irão se reorganizar. A dialógica ordem/ruído/ desordem/ordem é auto-organizativa, constituindo-se condição indispensável para o aumento da complexidade do sistema, conferindo-lhe maior autonomia. Portanto, para sua evolução, o organismo dependerá de relações que lidem com sua estabilidade, regularidade, que se apresentam no acaso, de forma imprevisível. Essa capacidade auto-organizativa dos sistemas vivos é denominada por Maturana e Varela (1995) de autopoiese e é caracterizada pela capacidade de autocriação dos sistemas em uma contínua produção de si mesmos.

\section{DISCUSSÕES FINAIS}

Os conceitos de Monod, Atlan, Maturana e Varela aqui apresentados facilitam a desconstrução de mapas cognitivos hierarquizadores, lineares, que buscam mecânicas de mundo. Colocam em evidência, por outro lado, a importância das crises, instabilidades, e também das regularidades. É necessária a inserção de princípios contraditórios para o desenvolvimento e manutenção dos sistemas. Nesse sentido, a tradição hindu sugere simbolicamente os deuses Shiva, que representa o movimento a transformação, e Brahma, definido como deus da conservação e da estabilidade. Entende-se que o risco se faz necessário, e a incerteza precisa ser aceita. Os problemas que assolam a humanidade implicam questões complexas e, portanto, necessita-se, conforme Gamboa (2006), capacitar na formulação de problemas complexos.

Morin (2002) destaca que é necessário a complexificação do pensamento, nos mais diferentes campos do conhecimento. Para ele, complexo é aquilo que se tece junto. Em seu entender, o complexo abraça, não deixa o outro, coloca o outro junto. Perceber a realidade em suas distintas dimensões é, portanto, fundamental para a integração de conhecimentos, a emergência no desenvolvimento de visões holísticas, contextualizadas, que resgatem a realidade em uma dimensão de totalidade, superando-se a fragmentação, a ordem, baseada em lógicas fixas e lineares produzida pela ciência moderna.

Para a superação de modelos lineares necessitamos compreender mudanças conceituais que definem essas distintas visões de mundo que apresentamos neste estudo. Sintetizamos essa tarefa no quadro que segue, num comparativo entre ciência clássica e complexidade. 
Liane Keite1 | Reginaldo Pereira

Ireno Antônio Berticelli

\section{Quadro 2 - ciência clássica e ciência da complexidade - comparações dos paradigmas fundantes}

\begin{tabular}{|c|c|c|}
\hline & Ciência Clássica & Complexidade \\
\hline Mundo & $\begin{array}{l}\text { - Mecânico, definido por } \\
\text { leis gerais }\end{array}$ & $\begin{array}{l}\text { - Distintos mundos. Sistemas mecânicos e } \\
\text { sistemas dinâmicos }\end{array}$ \\
\hline Realidade & $\begin{array}{l}\text { - Regularidade e equilíbrio } \\
\text { - Dualidade } \\
\text { - Ordem como processo } \\
\text { de organização }\end{array}$ & $\begin{array}{l}\text { - Regularidade e instabilidade são comple- } \\
\text { mentares } \\
\text { - Holística } \\
\text { - Ordem /desordem/ novos níveis de organi- } \\
\text { zação }\end{array}$ \\
\hline Trajetória & $\begin{array}{l}\text { - Definida a partir } \\
\text { de condições iniciais }\end{array}$ & $\begin{array}{l}\text { - Somente em sistemas mecânicos é possível } \\
\text { definir trajetórias. } \\
\text { - Sistemas dinâmicos: em alguns é possível } \\
\text { definir possibilidades em curto prazo, além } \\
\text { disto, as estruturas dissipativas estão à } \\
\text { mercê do acaso e têm a capacidade de } \\
\text { auto-organização a partir do caos. }\end{array}$ \\
\hline Leis de movimento & $\begin{array}{l}\text { - Definição de leis gerais. } \\
\text { - Busca as variáveis que } \\
\text { causam o movimento. } \\
\text { - DETERMINISMO LINEAR }\end{array}$ & $\begin{array}{l}\text { - Sistemas dinâmicos. } \\
\text { - Principalmente as estruturas dissipativas } \\
\text { funcionam a partir de correlações linguísticas. } \\
\text { - DETERMINISMO RECÍPROCO }\end{array}$ \\
\hline Sujeito Objeto & $\begin{array}{l}\text { - Dissociação } \\
\text { - Sujeito acima do objeto } \\
\text { - Dissociação entre ciên- } \\
\text { cias físicas e ciências } \\
\text { humanas }\end{array}$ & $\begin{array}{l}\text { - Sujeito objeto imbricados pelo linguajar } \\
\text { - Ciências humanas e ciências físicas como } \\
\text { um campo de ressonâncias }\end{array}$ \\
\hline Pesquisa & $\begin{array}{l}\text { - Generalização e univer- } \\
\text { salização } \\
\text { - Problemas disciplinares } \\
\text { com recortes restritos a } \\
\text { partir do recorte teórico } \\
\text { da especialidade }\end{array}$ & $\begin{array}{l}\text { - Regionalização e Localização } \\
\text { - Interdisciplinaridade e transdisciplinaridade, } \\
\text { buscando-se as diferentes dimensões da } \\
\text { realidade }\end{array}$ \\
\hline Tempo & $\begin{array}{l}\text { - Linear, cronológico, } \\
\text { causal }\end{array}$ & $\begin{array}{l}\text { - Irreversível, à mercê do acaso e da neces- } \\
\text { sidade gerando desordem e a partir disso } \\
\text { organizações mais complexas }\end{array}$ \\
\hline Identidade & $\begin{array}{l}\text { - Fixa. } 0 \text { sujeito é. } \\
\text { - Os organismos são } \\
\text { autônomos. }\end{array}$ & $\begin{array}{l}\text { - Contínuo processo de produção de si } \\
\text { mesmo. } 0 \text { sujeito precisa se autoproduzir } \\
\text { constantemente sob pena de perda de } \\
\text { identidade, estando em constante produção. } \\
0 \text { sujeito está sendo. } \\
\text { - A autonomia depende de uma ecologia. } \\
\text { Auto/eco/organização }\end{array}$ \\
\hline
\end{tabular}


Diante desse quadro, percebe-se que o desafio que se coloca é grande e faz-se necessário desenvolver novas posturas na produção do conhecimento, pois o caminho que aqui se propõe é o da complementaridade, da integração, da comunicação e da interlocução, do caos muito mais do que da ordem, do coletivo muito mais que do individual. Essa caminho nos desafia a ações inter e transdisciplinares, para que possamos tecer redes na produção do conhecimento com práticas decorrentes. Entendemos que os paradigmas abordados anteriormente são metáforas acerca do mundo que facilitam as interlocuções, as articulações e ligações entre as diferentes dimensões da realidade, para pensarmos e sermos capazes de transcender as nossas engessadas estruturas de pensar e agir, sendo que no seio desse processo ainda precisamos incluir o sentir com intensidade.

São muitos os elementos que podem ser buscados no Quadro II, a partir dos quais a própria educação como sistema e o educando podem ser ressignificados: dificilmente se sustenta, ante o quadro, um conceito de educação do tipo "o professor ensina e o educando aprende aquilo que o professor ensinou”, pura e simplesmente. Somos sistemas dinâmicos e autopoiéticos, de sorte que a dinâmica segundo a qual estamos constituídos em cada momento determina o modo de recepção dos conteúdos ensinados. O conteúdo é filtrado e reelaborado pelo educando. Decorre disso não a simples rejeição das provas escolares/acadêmicas, mas a própria expectativa que devemos ter sobre sua significação, em termos de avaliação do/da estudante, quando regularidade e instabilidade são complementares e quando somente em sistemas mecânicos é possível definir trajetórias, o que é muito diferente em sistemas dinâmicos. Por outro lado, até quando se sustenta a atual divisão rígida entre ciências humanas e ciências da naturęa, quando, na verdade, tudo é natureza? Não deveremos buscar também nas ciências ditas da natureza o que estamos buscando nas ciências ditas humanas e vice-versa? O quadro parece dirimir muitas dúvidas a respeito disto. Na pesquisa, até quando perdurará o estranhamento tão profundo entre sujeito e objeto? Não terá chegado há muito o tempo em que já dispomos de suficientes elementos para estabelecer, na pesquisa, uma relação intersubjetiva com o mundo/a natureza? Por outro lado, também é chegado o tempo, e já há elementos para propiciar um encontro dialógico entre os cientistas dos diferentes campos com os educadores, e destes com aqueles. Não podemos esquecer que também os seres humanos são natureza com o mundo, guardadas as diferenças que em tudo há. Como todos somos seres de linguagem, esta possibilita entendimentos e acordos mais que necessários e urgentes em educação: uma aproximação e integração dos saberes de forma efetiva, pragmática, através de discursos performativos que produzam conhecimentos transversais, pela efetiva transdisciplinaridade. A essa rodada de trocas, todos estamos convidados, cada qual podendo contribuir com o que melhor sabe. 


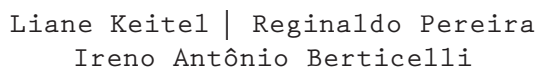

\section{BIBLIOGRAFIA}

ATLAN, Henri. Entre o cristal e a fumaça: ensaio sobre a organização do ser vivo. Rio de Janekro: Zahar, 1992.

ÁVILA, Fernando Dias de. Fundamentos históricos da ecologia. Ribeirão Preto: Holos, 1999. BERTALANFFY, Ludwig von. Teoria geral dos sistemas. 3.ed. Petrópolis: Vozes, 1977.

BOSCOLO, Luigi. A evolução do modelo sistêmico: da cibernética de primeira ordem à cibernética de segunda ordem. In: ELKAÏM, Mony (org.). Terapia familiar em transformação. São Paulo: Summus, 2000. p. 92-96.

FAZENDA, Ivani C. A. Interdisciplinaridade: história, teoria e pesquisa. Campinas: Papirus, 1994. FOERSTER, Heiz von. Observar a auto-referência em emergência. In: ELKAÏM, Mony (org.). Terapia familiar em transformação. São Paulo: Summus, 2000. p. 173-178.

. Visão e conhecimento: disfunções de segunda ordem. In: SCHNITMAN, Dora Fried (org.). Novos paradigmas, cultura e subjetividade. Porto Alegre: Artes Médicas, 1996. p. 59-74.

FREI BET'TO. HTTP:www.geocities.com/Vienna/2809/Betto.html. Acesso em 07.07.2006. GAMBOA, Sílvio. Palestra proferida na Universidade Comunitária da Região de Chapecó - UNOCHAPECÓ - Curso de Formação para a Pesquisa (não publicada). 2006.

MATURANA, Humberto. Emoções e linguagem na educaşão e na politica. Ed. UFMG, 1999.

MATURANA, Humberto \& VARELA, Francisco. A árvore do conhecimento: as bases biológicas da compreensão humana. São Paulo: Palas Athena, 2003.

MONOD, Jacques. O acaso e a necessidade: ensaio sobre a filosofia natural da biologia moderna. 6. ed. Petrópolis: Vozes, 2006.

MORIN, E. O problema epistemológico da complexidade. Portugal: Publicações Europa-América Ltda., 2002.

. O método 5: a humanidade da humanidade. Porto Alegre: Sulina, 2002.

ODUM, Eugene P. Ecologia. Rio de Janeiro: Guanabara Koogan, 1983.

PRIGOGINE, Ilya. O fim da ciência? In: SCHNITMAN, Dora Fried (org.). Novos paradigmas, cultura e subjetividade. Porto Alegre: Artes Médicas, 1996. p. 25-40.

Dos relógios às nuvens. In: SCHNITMAN, Dora Fried (org.). Novos paradigmas, cultura e subjetividade. Porto Alegre: Artes Médicas, 1996. p. 257-269.

Ressonâncias e campos do saber. In: ELKAÏM, Mony (org.). Terapia familiar em transformação. São Paulo: Summus, 2000, p. 210-216.

PRIGOGINE, Ilya \& STENGERS, Isabelle. A nova aliança: metamorfose da ciência. Brasília: Universitária, 1984.

SANTOS, Boaventura de Souza. Pela mão de Alice: o social e o político na pós-modernidade. 9. ed. São Paulo: Cortez, 2003.

VARELA, Francisco. As múltiplas figuras da circularidade. In: ELKAÏM, Mony (org.). Terapia familiar em transformação. São Paulo: Summus, 2000. p. 151-155.

WATZLAWICK, Paul; BEAVIN, Janet Helmick; JACKSON, Don. D. Programática da comunicação humana. [s.1]: Cultrix, [2000?].

WHITEHEAD, A. N. A ciência e o mundo moderno. São Paulo: Paulus, 2006.

Data de recebimento: 22/04/2010

Data de aprovação: 21/10/2011

Data da versão final: 02/12/2011 